\title{
Electronic Records Adoption in Archive Management in Djibouti's Academic Libraries: Barriers and the Role of Knowledge Sharing
}

\author{
Nimaleh Abdi Kabel'1, Jinyuan Zhou', Isidore Komla Zotoo², Wencheng Su1 \\ ${ }^{1}$ Institute of Science and Technology Information, Jiangsu University, Zhenjiang, China \\ ${ }^{2}$ School of Management, Jiangsu University, Zhenjiang, China \\ Email: hazard2015@hotmail.com,1000007163@ujs.edu.cn, zotook@yahoo.com,Bao5ye@163.com
}

How to cite this paper: Kabel, N.A., Zhou, J.Y., Zotoo, I.K. and Su, W.C. (2021) Electronic Records Adoption in Archive Management in Djibouti's Academic Libraries: Barriers and the Role of Knowledge Sharing. Open Access Library Journal, 8: e7116.

https://doi.org/10.4236/oalib.1107116

Received: December 27, 2020

Accepted: February 21, 2021

Published: February 24, 2021

Copyright $\odot 2021$ by author(s) and Open Access Library Inc.

This work is licensed under the Creative Commons Attribution International License (CC BY 4.0).

http://creativecommons.org/licenses/by/4.0/

\begin{abstract}
Quality library service depends partially on librarian capability and the adoption and use of technologies that enhance productivity. The perceived adoption and use (PAU) of electronic records management (ERM) in archiving were investigated in four academic libraries in Djibouti. The effects of capability of Librarians to use ERM (CAP) on knowledge sharing (KS), the effects of $\mathrm{CAP}$ on PAU, and the mediation potential of KS on the relationship between $\mathrm{CAP}$ and PAU were studied using structural equation modeling-partial least square design (SEM-PLS). Findings showed that CAP weakly influenced PAU, but did so significantly when considered with KS. This confirmed the mediating potential of KS. CAP also positively influenced KS among Librarians. The weak effect of CAP on PAU could be further investigated by considering other factors that define both library and personnel capabilities for ERM adoption. The study implied that KS should be practiced along with capacity development of Librarians in order to enhance PAU in Djibouti's libraries.
\end{abstract}

\section{Subject Areas}

Archaeology, Education, Information Science, Library, Intelligence and Philology

\section{Keywords}

Academic Libraries, Knowledge Sharing, Librarian Capabilities, Electronic Records Management

\section{Introduction}

Records management (RM) as a theory describes the efficient and systematic 
aspects of controlling the creation, receipt, maintenance, use and disposition of records. It also includes the processes used to capture and maintain evidence of activities and transactions in the form of records. The adoption of electronic records in the management (ERM) of archives in academic institutions ensures that they have the records and they are easily accessible whenever needed. ERM also influences how the institutions and individuals adopt and use information technologies in decision making [1]. Electronic records have become transformative in documentation and communication because they make storing, retrieving, using, transferring, analyzing and sharing information from records easy and with less effort. ERM has also been linked to reduction in administrative cost by other scholars [2] [3] [4]. The management of records on archives based on hardcopy documents is not sustainable especially with large volumes of information. All the functions of records management and archiving can be done with few personnel and within shorter periods using electronic means unlike for the use of hardcopy documents which are more laborious and time-consuming [2]. Paperless systems advocacy has led to a higher adoption of digital and electronic systems. Some studies have been done on paper use sustainability and one of the recommendations was to reduce its use through alternative means such as ERM in libraries [5]. In academic libraries, a lot of space can be saved by storing digital forms of records online or on computers in huge numbers instead of structuring space for hardcopies, which is unsustainable to a large extent [6]. ERM also gives the opportunity to update, delete or save records [7]. In fact, the advantages of adopting and using ERM in archive management by academic libraries are enormous [8] [9] [10].

In recent times, universities admit large numbers of students who need regular access to information from libraries. The use of electronic archiving allows academic libraries to categorize and save almost all relevant information on websites where this information is accessible to students regardless of space and distance [11]. Most academic libraries, especially in developed parts of the world use this system to make millions of literatures available to both students and faculty [12] [13]. This system of records keeping also enables several security features that prevent unauthorized access and use of information, as well as makes it easier to monitor usage and preferences of users [7]. For example, the number of times a particular document is open and read can be monitored among others and this helps in understanding the information seeking behavior of users through data generated. In all, ERM in archive management increases organizational efficiency despite the challenges faced by some in adopting and using such technology [14] [15].

One of the major barriers to the adoption of ERM in archive management is many universities is the lack of adequate capability, evident at both administrative and employee levels. Thus, both administrative efforts and capabilities to invest in and adopt electronic record keeping are inadequate or lacking, or that employees of such academic institutions lack the capability to use ERM. Capa- 
bility is therefore a major factor in the adoption and use of ERM. A study done in Yemen showed how relevant it was to have institutional, legal, financial and structural readiness as capability for the adoption of ERM in higher professional education institutions [14]. According to the study, academic institutions were advised to provide adequate resources towards adopting ERM. Another study carried out in Nigeria revealed how the lack of awareness of ERM at the management levels in federal universities hindered its adoption and use [15]. The challenge of capability is common among developing parts of the world where certain infrastructural inadequacies and inefficiencies make the adoption of such technologies daunting [14] [15]. Some of the main challenges are lack of awareness or knowledge [15], lack of financial capability, expert and technical support [16] and structural support and high maintenance cost [17] among others. Beside financial and infrastructural concerns, some key challenges which seem to recur are lack of awareness and technical expertise, pointing to an urgent need for knowledge acquisition and sharing to build institutional and individual capability.

Knowledge sharing simply describes how acquired knowledge or expertise is transferred between persons or institutions and is important in capacity building [18] [19] [20] [21] [22]. It is one of the easiest ways of multiplying the positive effects of knowledge acquisition. Owing to the advantage attached to ERM in archive management, it is laudable that experts in the subject transfer or share knowledge with others within or without their organizations. The transfer of such technical expertise at varying levels intra and inter-organizations is relevant to help minimize the effects of technical incapability on ERM adoption and use in public universities. Knowledge sharing is therefore considered in this study a tool that can be used to increase the adoption of ERM in academic libraries in the management of archives. The aim of this study is to study the adoption of ERM in archive management in Djibouti's academic libraries, the barriers and the role of knowledge sharing. The study specifically looks at the effect of technical readiness of selected Djibouti's academic libraries on the adoption of ERM in archive management, considering the role of knowledge sharing.

Through a cross-sectional survey, this study assessed the effects of capability of Librarians to use ERM (CAP) on knowledge sharing (KS), the effects of CAP on PAU, and the mediation potential of KS on the relationship between CAP and PAU using structural equation modeling-partial least square design (SEM-PLS).

\section{Theoretical Framework and Hypothesis Development}

According to some studies done in the past, academic libraries have had difficulty in the cataloging and management of electronic journals and documents. Such records were difficult to manage because of many challenges such as process complexity, maintenance challenges especially with the identification and fixing of broken linkages, and authoritative guidance on electronic journal 
cataloging [23]. Many other studies have followed concerning ERM adoption in academic institutions and libraries across the world. The emergence and the urgency of going electronic in academic libraries is becoming a major focus in the $21^{\text {st }}$ century and ERM is transforming both academic libraries and librarians by changing the status-quo [24]. With enormous increase in the preference for electronic journals and books, many academic libraries are being challenged to adopt and use ERM in their management of records and this has exposed both the strengths and weaknesses of some institutions, while shaping their strategies for future competition [25]. The adoption of different technologies that make it possible for academic libraries to adopt ERM is key to a successful and sustainable transformation [25]. The use of electronic records with active links on networked online platforms to allow access and use of electronic resources is becoming the trend in academic libraries in the $21^{\text {st }}$ century and the trajectory shows that further sophistications can be expected in the coming years.

A characteristic feature of ERM in archiving electronic resources is the ease of accessibility; and this is a major feature used by academic libraries on networked and shared platforms where such resources can be accessed by users. Being a game-changer in the $21^{\text {st }}$ century and beyond, ERM in archives management in academic libraries is becoming the focus. A study was done to measure the use of ERM in academic library consortium in Ontario, Canada, and results showed that there is an increasing pressure in academic libraries due to high demands placed on networked electronic documents. Worth mentioning, the electronic records created to manage academic documents in archives become the tool for networked electronic libraries and databases [26]. Being used appropriately, users can retrieve journals and books through self-servicing networked platforms made available by academic libraries.

Many approaches have been used to study ERM adoption and use in academic libraries. Most of them are quantitative and of a cross-sectional survey design. Whereas the relevance of ERM in academic libraries and experiences from its adoption and use have been reviewed by some scholars [3] [4] [7] [17] [23] [25] [26] [27], others have also considered the readiness and capabilities of academic institutions towards the adoption and use of ERM in electronic records archiving in academic libraries [14] [15] [27].

It is rare to find literature on the adoption and use of ERM in academic libraries in Djibouti. No literature has been found so far, during the time of this study, on ERM use in academic libraries in Djibouti. However, considering the commonality of technological and infrastructural challenges within the East African sub-region and other developing parts of the world, inferences can be made from other studies. The lack of information about Djibouti may be due to the low level of research output from librarians within the geographical setting or the lack of interest in the subject [28]. Although there is only one university in Djibouti, there are a few privately owned and state-owned libraries, mostly through partnerships with international academic institutions. Librarians in 
some of these libraries have undergone some training to use ERM in archiving and managing electronic journals and books. Some of these trainings cut across the African continent as well [29]. This study basically considers how much knowledge sharing in ERM has impacted the capabilities of four academic libraries in Djibouti to adopt and use ERM in electronic document archiving. Based on this objective and the effect of knowledge sharing on innovative capability of organizations [20] [30], the following hypotheses have been developed:

$\mathrm{H1}$ : the capability of personnel in academic libraries will influence the adoption and use of ERM;

H2: academic librarians' capability to adopt and use ERM will influence their ability to share knowledge; and

H3: Knowledge sharing will indirectly influence the relationship between capability and ERM adoption in Djibouti's academic libraries.

\subsection{Technical Capability and Technology Acceptance Model}

Many studies have been done to assess the technology acceptance model (TAM) and to understand the factor surrounding the acceptance of any technology such as the ERM investigated in this study. Park et al. (2009) investigated user acceptance of digital library system in developing countries using data from a survey of 16 institutions in Africa, Asia, and Central/Latin America $(N=1082)$. According to the study, a path analysis revealed that perceived ease of use of the library system had a significant impact on perceived usefulness, which ultimately led to behavioral intention to use [31]. The ease of use of every technology is a key factor in determining the level of acceptance, and this is significantly hinged on capability development. Another study showed that perceived usefulness, interactivity, and ease of use had significant effects on user attitude and intention to use mobile library applications [32]. Several other scholars have confirmed that the ability to use electronic technologies easily increases its acceptance rate significantly [33] [34] [35]. There is always a relationship between capability and adoption and is some areas such as academic libraries, there are ethical considerations of capacity building to use ERM where there is a need for compliance to standards [36].

\subsection{Effect of Knowledge Sharing on Technical Capability}

Owing to the link observed between ease of use or the capability to use technologies and the adoption of same, it is important to assess the role of knowledge sharing. Knowledge sharing in its basic form is a means of transferring knowledge about a skill or a technology. Without much emphasis, knowledge sharing positively influences capability and individual and collective innovation as the earlier is synonymous with training and learning [18] [19] [20] [21] [22]. This study therefore expects that knowledge sharing among librarians will positively influence their capability to adopt and use ERM in archiving of electronic resources in academic libraries in Djibouti, hence $\mathrm{H} 2$. 


\subsection{Conceptual Framework}

The theoretical underpinnings of the hypotheses and the relationships between variables of the study are represented in Figure 1. From the framework, a two-way relationship between knowledge sharing and capability are shown, whereas, capability is expected to influence perceived adoption and use of ERM. Knowledge sharing is expected to mediate the relationship between capability and ERM adoption and use Figure 1.

\section{Methodology}

\subsection{Study Design and Sampling}

The study follows a cross-sectional, survey design and is quantitative in nature. Being cross-sectional, data was collected once and analyzed to draw conclusions based on results [37]. Four academic libraries in Djibouti were the sampling population and frame of the study. Due to the low number of libraries available in Djibouti, all library staff whose job descriptions concern records of library books and electronic resources management were involved in the study. A total of 63 respondents, purposively sampled participated as study units to whom questionnaires were administered.

\subsection{Data Gathering Process}

Structured, itemized questionnaires were developed to gather data from respondents on three study variables, capability to use ERM (CAP), knowledge sharing (KS) and perceived ERM adoption and use (PAU). Using a 5-point Likert scale $(1$ = disagree strongly, 2 = disagree, $3=$ neither agree nor disagree, $4=$ agree, $5=$ agree strongly), PAU was assessed with 6 questions, followed by 5 questions for KS and 7 for CAP, totaling 18 questions. Questionnaires were piloted and updated for clarity using 10 library staff. In all, sixty-three (63) questionnaires were administered in 3 academic libraries by face-to-face mode and a 100\% response rate was achieved.

\subsection{Data Analysis}

\subsubsection{Path Analysis Using SEM-PLS}

Data were organized using Microsoft Excel spreadsheet and saved in the csv format for further processing and analysis using SmartPLS3 statistical software. Mean scores for all questions were used to measure the study variables. The structural equation modelling was done using the partial least square design. Data fitness was done using the Cronbach's alpha values, convergent validity, multiple collinearity, normality and composite reliability tests. A 95\% confidence interval was used to confirm statistical significance of results. Path analysis was done to measure the relationships between constructs.

\subsubsection{Test of Mediation}

The direct effect of CAP on PAU is given by $\mathrm{p} 1$ and the indirect effect is given by 


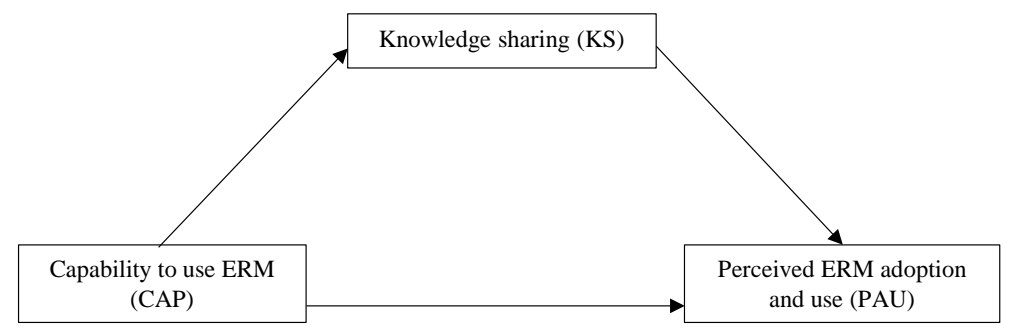

Figure 1. Conceptual framework.

$\mathrm{p} 2{ }^{\star} \mathrm{p} 3$ (Figure 2). If $\mathrm{p} 1>\mathrm{p} 2{ }^{\star} \mathrm{p} 3$, then KS does not have any mediation effect. However, if $\mathrm{p} 2{ }^{*} \mathrm{p} 3>\mathrm{p} 1$, then KS is a significant mediator. To investigate further if the mediating role of KS is complementary or competitive, the product of all path coefficients is taken $\left(\mathrm{p} 1{ }^{*} \mathrm{p} 2{ }^{*} \mathrm{p} 3\right)$ (Figure 2$)$. If the product gives a positive value, then the mediation is complementary. However, a negative value depicts competitive mediation effect.

\section{Results and Discussion}

\subsection{Fitness of Data}

Data were normally distributed without multicollinearity (VIF $<5$ ). Cronbach's alpha values averaged 0.88 , showing high covariance and ensuring construct reliability and internal consistency. Convergent validity test was done and the factor loadings for each variable in constructs ranged from 0.60 to 0.89 . The average variance extracted (AVE) was $>0.50<$ composite reliability (CR) (Table 1) [38] [39]. Based on requirement that AVE values of each is higher than the squared correlation among the constructs, the discriminant validity (DV) of constructs was tested. Using an oblique rotation of correlated factors, correlations below 0.6 DV of constructs (Table 2). The validity of the model, based on the $\mathrm{R}^{2}$ values for the three constructs, was confirmed as $0.802,0.747$, and 0.665 for CAP, KS and PAU, respectively.

\subsection{PLS Path Analysis and Test of Hypotheses}

\subsubsection{Direct Relationship between CAP and PAU}

From path analysis of data, the path coefficient between CAP and PAU showed a positive but weak correlation between the two (0.282) (Figure 3). This showed that CAP positively influences PAU. Thus, the more librarians are able to use or the higher the technical ability of librarians to use ERM technologies, the higher the rate of ERM adoption in academic libraries in Djibouti. This reiterates findings of other researchers which confirmed that capability development leads to innovation; in this regard, the adoption and use of ERM in archive management [40] [41] [42] [43] [44]. The implication of this result is that, individual librarians who acquire technical knowledge and skills in ERM will become more efficient, innovative and resourceful in managing records of resources in academic libraries in order to remain competitive. This is especially important for privately-owned academic libraries that are sustained by client patronage and economic 
gains. This also applies to state-owned libraries in term of remaining competitive as far as academic ranking is concerned, considering its effect on international and local reputation and student enrolment [45].

In the context of the analysis and the support from literature so far, $\mathrm{H} 1$ (the capability of personnel in academic libraries will influence the adoption and use of ERM), is accepted.

Table 1. Data reliability and convergence.

\begin{tabular}{|c|c|c|c|c|c|}
\hline Construct (factors) & Items & Factor analysis & AVE & CR & Cronbach's alpha \\
\hline \multirow{7}{*}{$\begin{array}{l}\text { Capability to use ERM } \\
\text { (CAP) }\end{array}$} & CAP1 & 0.72 & \multirow{7}{*}{0.60} & \multirow{7}{*}{0.74} & \multirow{7}{*}{0.84} \\
\hline & CAP2 & 0.77 & & & \\
\hline & CAP3 & 0.68 & & & \\
\hline & CAP4 & 0.88 & & & \\
\hline & CAP5 & 0.60 & & & \\
\hline & CAP6 & 0.69 & & & \\
\hline & CAP7 & 0.85 & & & \\
\hline \multirow{5}{*}{ Knowledge sharing (KS) } & KS1 & 0.78 & \multirow{5}{*}{0.73} & \multirow{5}{*}{0.82} & \multirow{5}{*}{0.93} \\
\hline & KS2 & 0.65 & & & \\
\hline & KS3 & 0.87 & & & \\
\hline & KS4 & 0.88 & & & \\
\hline & KS5 & 0.70 & & & \\
\hline \multirow{6}{*}{$\begin{array}{c}\text { Perceived adoption and use } \\
\text { of ERM (PAU) }\end{array}$} & PAU1 & 0.89 & \multirow{6}{*}{0.67} & \multirow{6}{*}{0.78} & \multirow{6}{*}{0.88} \\
\hline & PAU2 & 0.71 & & & \\
\hline & PAU3 & 0.89 & & & \\
\hline & PAU4 & 0.65 & & & \\
\hline & PAU5 & 0.65 & & & \\
\hline & PAU6 & 0.88 & & & \\
\hline
\end{tabular}

Table 2. Discriminant validity of factors.

\begin{tabular}{llll}
\hline Factors & 1 & 2 & 3 \\
\hline 1. Capability to use ERM (CAP) & 0.53 & & \\
2. Knowledge sharing (KS) & 0.42 & $\mathbf{0 . 5 0}$ & \\
3. Perceived adoption and use of ERM (PAU) & 0.41 & 0.44 & $\mathbf{0 . 4 8}$ \\
\hline
\end{tabular}

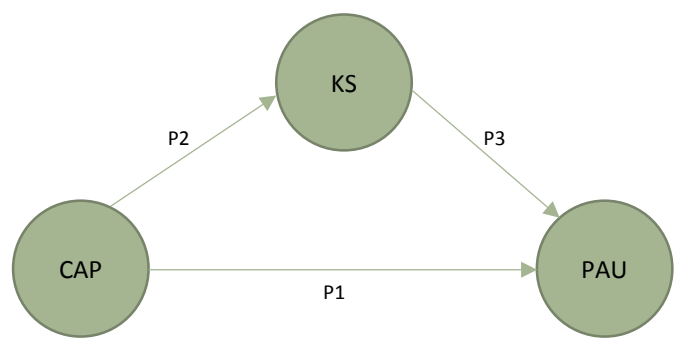

Figure 2. Analytical framework for measuring mediation effect of KS. CAP = capability to use ERM, KS = knowledge sharing and $\mathrm{PAU}=$ perceived adoption and use of ERM. 


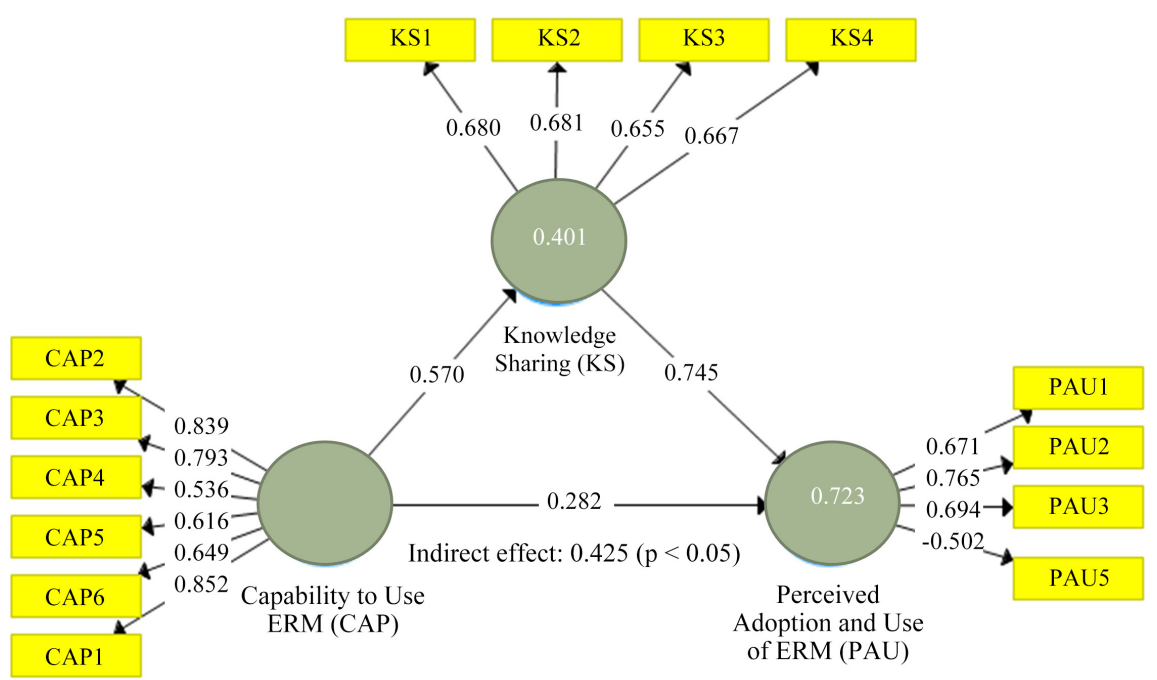

Figure 3. PLS-SEM path model and analysis of the relationships between variables.

\subsubsection{Direct Relationship between KS and CAP}

The effect of CAP on KS of librarians in Djibouti, with a path coefficient of 0.570 was found to be significant and positive $(\mathrm{p}<0.05)$ (Figure 3$)$. The observed relevance placed on CAP in Djibouti's libraries is reflective of its scarcity as such skills in ERM among Librarians may be in short supply. From a practical perspective, KS leads to the creation of new knowledge. For example, in the context of multiplier effect in personnel training and capacity development, when knowledge gained from training is shared by an individual to other individuals, new knowledge is created and capacities are built upon. In this same context, it is expected that KS will further build librarians capacity to use ERM in archiving. According to a study done in Nigeria, KS was found to have led to enhanced effectiveness among librarians. Also, it further increased their ability to make new discoveries and to be more innovative [46]. Another similar study done in Nigerian universities showed that knowledge management, which included knowledge creation (KC.), KS and knowledge application (KA) had positive and significant effect on service innovation in libraries. The study concluded that university libraries in Nigeria with high activities in KC, KS and KA are more likely to provide innovative services to users [47].

Notwithstanding, the effect of KS on CAP is such that when CAP is enhanced, there is a higher likelihood of KS [48]. Thus, knowledge can only be shared when there is already capability. A trained personnel or Librarian with capability to use ERM is poised and capable of sharing knowledge to help other who need same. This relationship was explained in the positive Pearson's correlation of $0.771(\mathrm{p}<0.05)$ between KS and CAP. The implication of this observation is that when the capabilities of Librarians in Djibouti's academic libraries are built, it encourages a higher level of knowledge sharing among them. Thus, while KS creates new knowledge and capability, it also indirectly leads to more KS. Hence, $\mathrm{H} 2$ (academic librarians capability to adopt and use ERM will influence their 
ability to share knowledge) is accepted.

\subsubsection{Indirect Effect of KS on PAU}

The indirect effect of KS on PAU was assessed by investigating its mediating role on the relationship between CAP and PAU. Thus, when the effect of CAP on PAU is enhanced by the presence of KS significantly, the latter is considered a mediator, either competitive or complementary as explained in methodology [49]. The product of the path coefficients between CAP and KS (0.570) and KS and PAU (0.745) was $0.425(\mathrm{p}<0.05)$, which was higher than the direct relationship between CAP and PAU (0.282). This showed that KS played a significant mediating role between CAP and PAU. Furthermore, the product of the three paths CAP-KS, KS-PAU and CAP-PAU $(0.570 \times 0.745 \times 0.282)$ was 0.120 , which meant that KS was a complementing the effect of CAP on PAU.

The implication of this finding to Djibouti's Librarians is that, KS should be practiced as a strategic objective alongside capacity building among Librarians in academic libraries in order to ensure that capabilities developed in ERM translate significantly into the actual adoption and use of ERM in archiving and management of resources. Therefore, H3 (Knowledge sharing will indirectly influence the relationship between CAP and PAU) is accepted.

\subsection{Barriers to ERM Adoption in Djibouti's Academic Libraries}

The challenges that make it difficult for academic libraries to adopt and use technologies that allow them to electronically manage records have been captured in this study. Five main categories of challenges were observed such as financial, infrastructural, managerial, private-public partnership and technical knowledge. The main challenges were financial difficulties (33\%) and inadequate technical knowledge (53\%) (Figure 4).

It is important to note that this study was able to adopt one of the major barriers to the adoption of ERM, which is inadequate technical knowledge. This was captured in the theories of KS and CAP as factors influencing PAU. Technical challenges of adopting ERM due to complex and isolated nature of data that need to be pooled together on an interface has been confirmed in a study [50]. Financial challenges to the adoption of ERM technologies are also common globally but especially in developing regions [51] [52] [53]. In another study, leadership was considered an important factor that significantly influences successful adoption of ERM [54]. The other factors such as infrastructure and partnership are well-known for their role in the adoption and use of technologies. While partnership allows for different parties to leverage on each other's strengths and support to overcome weaknesses, infrastructure provides the needed tools for a successful adoption, use and maintenance of technologies. The case of academic libraries in Djibouti in terms of the barriers faced in adopting ERM is a common one and this study serves as a baseline to further advance the understanding of ERM adoption and use in their academic libraries. 


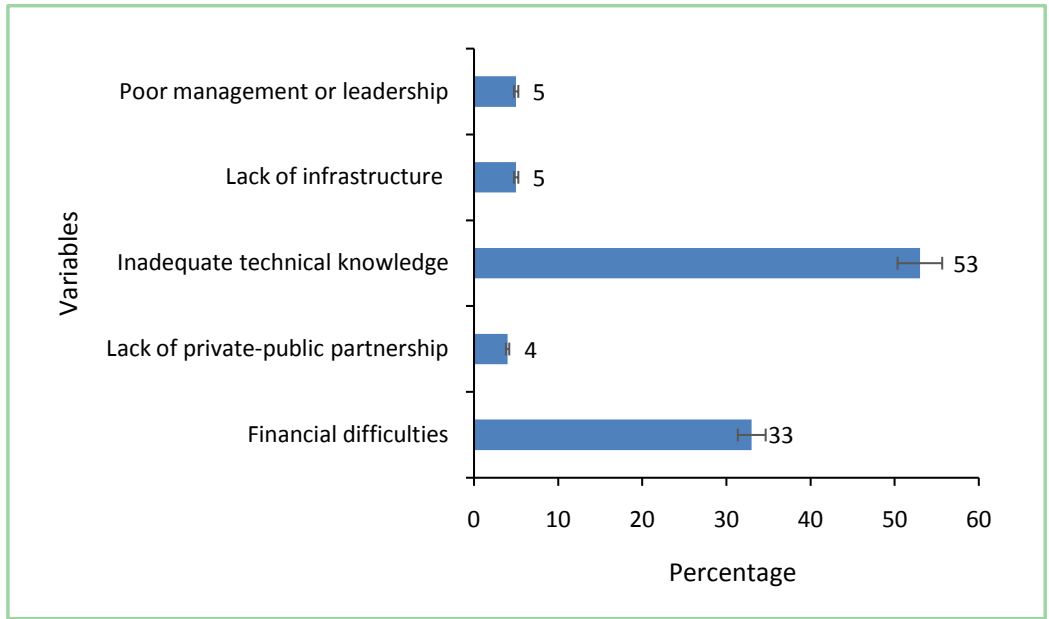

Figure 4. Barriers to ERM adoption in academic libraries in Djibouti.

\section{Conclusions}

The literature gap on the state of academic libraries in Djibouti in the context of ERM in archiving has been partially filled in this study. The relationships between KS, CAP and PAU were investigated and results showed that CAP led to a significant increase in KS among librarians; that CAP enhanced PAU, although the relationship was weak; and that KS significantly played a complementary mediation role in enhancing the effect of CAP on PAU. The major barriers to the adoption and use of ERM in Djibouti's academic libraries were inadequate technical knowledge and financial difficulties.

The major limitation of the study was the difficulty to gather high number of respondents due to the limited number of academic libraries in Djibouti, given the fact that it is a country of less than one million people in East Africa. Although this did not affect the significance and the appropriateness of data in the study, it did not give researchers the comfort of dealing with large numbers expected for quantitative assessment.

It is recommended that future studies focus on other factors that define the capability of libraries in Djibouti and not only the capability of academic librarians to adopt ERM.

\section{Acknowledgements}

This work was supported by new technical Information consultation of hospital (No. 20200057).

\section{Conflicts of Interest}

The authors declare no conflicts of interest regarding the publication of this paper.

\section{References}

[1] Hedstrom, M. (1991) Understanding Electronic Incunabula: A Framework for Re- 
search on Electronic Records. The American Archivist, 54, 334-354. https://doi.org/10.17723/aarc.54.3.125253r60389r011

[2] Matangira, V., Katjiveri-Tjiuoro, M. and Lukileni, N.H. (2015) Establishing a University Records Management Programme: A Case Study of the University of Namibia. Journal for Studies in Humanities and Social Sciences, 2, 103-117.

[3] Cook, T. (1994) Electronic Records, Paper Minds: The Revolution in Information Management and Archives in the Post/Custodial and Post/Modernist Era. [Based on a Presentation Delivered by the Author during His November 1993 Australian Tour.]. Archives and Manuscripts, 22, 300-329.

[4] Raas, U. (1999) Electronic Recordkeeping-More than Electronic Document Management. Records Management Journal, 9, 117-129. https://doi.org/10.1108/EUM0000000007246

[5] Adams, R., et al. (2004) Promoting Sustainable Paper Use in the Killam Library.

[6] Johnson, J.J. and McElroy Jr., J.R. (1998) Computer Based Records Management System Method. US Patents No. US5813009A.

[7] Johnston, G.P. and Bowen, D.V. (2005) The Benefits of Electronic Records Management Systems: A General Review of Published and Some Unpublished Cases. Records Management Journal, 15, 131-140. https://doi.org/10.1108/09565690510632319

[8] Zach, L. and Peri, M. (2010) Practices for College and University Electronic Records Management (ERM) Programs: Then and Now. The American Archivist, 73, 105-128. https://doi.org/10.17723/aarc.73.1.u068w277852n25m8

[9] Stewart, C. (2012) Preservation and Access in an Age of E-Science and Electronic Records: Sharing the Problem and Discovering Common Solutions. Journal of Library Administration, 52, 265-278. https://doi.org/10.1080/01930826.2012.684505

[10] Michalak, S.C. (2012) This Changes Everything: Transforming the Academic Library. Journal of Library Administration, 52, 411-423.

https://doi.org/10.1080/01930826.2012.700801

[11] Madhusudhan, M. and Nagabhushanam, V. (2012) Web-Based Library Services in University Libraries in India: An Analysis of Librarians' Perspective. The Electronic Library, 30, 569-588. https://doi.org/10.1108/02640471211275657

[12] Saunders, L. (2009) The Future of Information Literacy in Academic Libraries: A Delphi Study. Portal: Libraries and the Academy, 9, 99-114. https://doi.org/10.1353/pla.0.0030

[13] Aghaei Chadegani, A. Salehi, H., Md Yunus, M., Farhadi, H., Fooladi, M., Farhadi, M., et al. (2013) A Comparison between Two Main Academic Literature Collections: Web of Science and Scopus Databases. Asian Social Science, 9, 18-26. https://doi.org/10.5539/ass.v9n5p18

[14] Mukred, M., Yusof, Z.M., Asma' Mokhtar, U. and Abdul Manap, N. (2016) Electronic Records Management System Adoption Readiness Framework for Higher Professional Education Institutions in Yemen. International Journal on Advanced Science, Engineering and Information Technology, 6, 804-811. https://doi.org/10.18517/ijaseit.6.6.1369

[15] Eze Asogwa, B. (2013) The Readiness of Universities in Managing Electronic Records: A Study of Three Federal Universities in Nigeria. The Electronic Library, 31, 792-807. https://doi.org/10.1108/EL-04-2012-0037

[16] Ajami, S. and Bagheri-Tadi, T. (2013) Barriers for Adopting Electronic Health Records (EHRs) by Physicians. Acta Informatica Medica, 21, 129-134.

https://doi.org/10.5455/aim.2013.21.129-134 
[17] Kruse, C.S., Kristof, C., Jones, B., Mitchell, E. and Martinez, A. (2016) Barriers to Electronic Health Record Adoption: A Systematic Literature Review. Journal of Medical Systems, 40, Article No. 252. https://doi.org/10.1007/s10916-016-0628-9

[18] Wuryaningrat, N.F. (2013) Knowledge Sharing, Absorptive Capacity and Innovation Capabilities: An Empirical Study on Small and Medium Enterprises in North Sulawesi, Indonesia. Gadjah Mada International Journal of Business, 15, 61-77. https://doi.org/10.22146/gamaijb.5402

[19] Wang, J., Yang, J. and Xue, Y. (2017) Subjective Well-Being, Knowledge Sharing and Individual Innovation Behavior. Leadership \& Organization Development Journal, 38, 1110-1127. https://doi.org/10.1108/LODI-10-2015-0235

[20] Liao, S.-H., Fei, W.-C. and Chen, C.-C. (2007) Knowledge Sharing, Absorptive Capacity, and Innovation Capability: an Empirical Study of Taiwan's Knowledge-Intensive Industries. Journal of Information Science, 33, 340-359.

https://doi.org/10.1177\%2F0165551506070739

[21] Le, P.B. and Lei, H. (2019) Determinants of Innovation Capability: The Roles of Transformational Leadership, Knowledge Sharing and Perceived Organizational Support. Journal of Knowledge Management, 23, 527-574.

https://doi.org/10.1108/JKM-09-2018-0568

[22] Curado, C., Oliveira, M., Maçada, A.C.G. and Nodari, F. (2017) Teams' Innovation: Getting There through Knowledge Sharing and Absorptive Capacity. Knowledge Management Research \& Practice, 15, 45-53. https://doi.org/10.1057/kmrp.2015.8

[23] West, W.L. and Miller, H.S. (2011) Electronic Journals: Cataloging and Management Practices in Academic Libraries. Serials Review, 37, 267-274. https://doi.org/10.1080/00987913.2011.10765401

[24] Ross, L. and Sennyey, P. (2008) The Library Is Dead, Long Live the Library! The Practice of Academic Librarianship and the Digital Revolution. The Journal of Academic Librarianship, 34, 145-152. https://doi.org/10.1016/j.acalib.2007.12.006

[25] Atkinson, J. (2021) Reflections on Technology, Change and Academic Libraries. In: Atkinson, J., Ed., Technology, Change and the Academic Library, Elsevier, Amsterdam, 185-193. https://doi.org/10.1016/B978-0-12-822807-4.00018-X

[26] Scigliano, M. (2010) Measuring the Use of Networked Electronic Journals in An academic Library Consortium: Moving beyond MINES for Libraries ${ }^{\circledR}$ in Ontario Scholars Portal. Serials Review, 36, 72-78. https://doi.org/10.1080/00987913.2010.10765287

[27] Sullenger, P. (2011) A Serials Format Inventory Project: How Far Can Academic Libraries Go with "Electronic Only"? Serials Review, 37, 174-180.

https://doi.org/10.1080/00987913.2011.10765380

[28] Ocholla, D., Ocholla, L. and Onyancha, O.B. (2012) Research Visibility, Publication Patterns and Output of Academic Librarians in Sub-Saharan Africa: The Case of Eastern Africa. Aslib Proceedings, 64, 478-493.

https://doi.org/10.1108/00012531211263102

[29] Katuu, S. (2013) An Overview of Archives and Records Management Education Training in Africa. 3rd Asia Pacific Conference in Archival Education, Innovation and Engagement, Beijing, October 2013, 1-24.

[30] Svetlik, I., Stavrou-Costea, E. and Lin, H.F. (2007) Knowledge Sharing and Firm Innovation Capability: An Empirical Study. International Journal of Manpower, 28, 315-332.

[31] Park, N., Roman, R., Lee, S. and Chung, J.E. (2009) User Acceptance of a Digital Library System in Developing Countries: An Application of the Technology Accep- 
tance Model. International Journal of Information Management, 29, 196-209. https://doi.org/10.1016/j.ijinfomgt.2008.07.001

[32] Yoon, H.-Y. (2016) User Acceptance of Mobile Library Applications in Academic Libraries: An Application of the Technology Acceptance Model. The Journal of Academic Librarianship, 42, 687-693. https://doi.org/10.1016/j.acalib.2016.08.003

[33] Kaasinen, E. (2005) User Acceptance of Mobile Services: Value, Ease of Use, Trust and Ease of Adoption. VTT Publications, Espoo.

[34] Featherman, M.S., Miyazaki, A.D. and Sprott, D.E. (2010) Sprott, Reducing Online Privacy Risk to Facilitate E-Service Adoption: The Influence of Perceived Ease of Use and Corporate Credibility. Journal of Services Marketing, 24, 219-229. https://doi.org/10.1108/08876041011040622

[35] Bose, R. (2003) Knowledge Management-Enabled Health Care Management Systems: Capabilities, Infrastructure, and Decision-Support. Expert Systems with Applications, 24, 59-71. https://doi.org/10.1016/S0957-4174(02)00083-0

[36] McLeod, J., Childs, S. and Heaford, S. (2007) Records Management Capacity and Compliance Toolkits: A Critical Assessment. Records Management Journal, 17, 216-232. https://doi.org/10.1108/09565690710833116

[37] Sedgwick, P. (2014) Cross Sectional Studies: Advantages and Disadvantages. BMJ, 348, g2276. https://doi.org/10.1136/bmj.g2276

[38] Fornell, C. and Larcker, D.F. (1981) Evaluating Structural Equation Models with Unobservable Variables and Measurement Error. Journal of Marketing Research, 18, 39-50. https://doi.org/10.1177\%2F002224378101800104

[39] Fornell, C. and Larcker, D.F. (1981) Structural Equation Models with Unobservable Variables and Measurement Error: Algebra and Statistics. Journal of Marketing Research, 18, 382-388. https://doi.org/10.2307/3150980

[40] Yeh, S.-T. and Ramirez, R. (2016) A Conceptual Model of Service Innovation: The Case of Academic Libraries.

[41] Singh, J. and Kaur, T. (2009) Future of Academic Libraries in India: Challenges and Opportunities. International Conference on Academic Libraries, Delhi, 5-8 October 2009.

[42] Pritchard, S.M. (1996) Determining Quality in Academic Libraries. Library Trends, 44, 572-594.

[43] Neal, J.G. (2001) The Entrepreneurial Imperative Advancing from Incremetal to Radical Change in the Academic Library. Portal: Libraries and the Academy, 1, 1-13. https://doi.org/10.1353/pla.2001.0006

[44] Islam, M.A., Agarwal, N.K.K. and Ikeda, M. (2015) Knowledge Management for Service Innovation in Academic Libraries: A Qualitative Study. Library Management, 36, 40-57. https://doi.org/10.1108/LM-08-2014-0098

[45] Lukman, R., Krajnc, D. and Glavič, P. (2010) University Ranking Using Research, Educational and Environmental Indicators. Journal of Cleaner Production, 18, 619-628. https://doi.org/10.1016/j.jclepro.2009.09.015

[46] Awodoyin, A., Osisanwo, T., Adetoro, Ni. and Adeyemo, I. (2016) Knowledge Sharing Behaviour Pattern Analysis of Academic Librarians in Nigeria. Journal of Balkan Libraries Union, 4, 12-19.

[47] Ugwu, C.I. and Ekere, J.N. (2018) The Role of Knowledge Management in Providing Innovative Services in University Libraries in Nigeria. Global Knowledge, Memory and Communication, 67, 350-376.

https://doi.org/10.1108/GKMC-10-2017-0086 
[48] Cabrera, E.F. and Cabrera, A. (2005) Fostering Knowledge Sharing through People Management Practices. The International Journal of Human Resource Management, 16, 720-735. https://doi.org/10.1080/09585190500083020

[49] Baron, R.M. and Kenny, D.A. (1986) The Moderator-Mediator Variable Distinction in Social Psychological Research: Conceptual, Strategic, and Statistical Considerations. Journal of Personality and Social Psychology, 51, 1173-1182.

https://doi.apa.org/doi/10.1037/0022-3514.51.6.1173

[50] McDonald, C.J. (1997) The Barriers to Electronic Medical Record Systems and How to Overcome Them. Journal of the American Medical Informatics Association, 4, 213-221. https://doi.org/10.1136/jamia.1997.0040213

[51] Jebraeily, M., Piri, Z., Rahimi, B., Ghasemzade, N., Ghasemirad, M. and Mahmodi, A. (2012) Barriers of Electronic Health Records Implementation. Director General, 8.

[52] Hasanain, R.A. and Cooper, H. (2014) Solutions to Overcome Technical and Social Barriers to Electronic Health Records Implementation in Saudi Public and Private Hospitals. Journal of Health Informatics in Developing Countries, 8, 46-63.

[53] Boonstra, A. and Broekhuis, M. (2010) Barriers to the Acceptance of Electronic Medical Records by Physicians from Systematic Review to Taxonomy and Interventions. BMC Health Services Research, 10, Article No. 231. https://doi.org/10.1186/1472-6963-10-231

[54] Silow-Carroll, S., Edwards, J.N. and Rodin, D. (2012) Using Electronic Health Records to Improve Quality and Efficiency: The Experiences of Leading Hospitals. Issue Brief (Commonwealth Fund), 17, 1-40. 